\title{
Rheological Behavior of Hydrogen Bonding Miscible Blend: High Molecular Weight Poly(2-vinyl pyridine) and Low Molecular Weight Poly(4-vinyl phenol)
}

\author{
Osamu Urakawa ${ }^{\dagger}$, Ayaka Yasue, and Tadashi Inoue \\ Department of Macromolecular Science, Osaka University, Toyonaka, Osaka 560-0043, Japan \\ (Received : February 24, 2021)
}

\begin{abstract}
We examined thermal and rheological behaviors for miscible polymer blends, poly(2-vinyl pyridine) / poly(4-vinyl phenol) $(2 \mathrm{VPy} / \mathrm{VPh})$, in which intermolecular hydrogen bonds play an important role. The molecular weights of the $2 \mathrm{VPy}$ and $\mathrm{VPh}$ components are higher and lower than the critical sizes of the entanglement, respectively. In the mixture of these two polymers, only the 2VPy chains entangle each other, and the low molecular weight VPh is expected to act as a diluent. We found that the time-temperature superposition principle approximately held. The Williams-Landel-Ferry equation with a single parameter set $\left(C_{1}\right.$ and $\left.C_{2}\right)$ could represent their shift factors by setting the reference temperatures to be $T_{\mathrm{g}}+64^{\circ} \mathrm{C}$. From the comparison of the composite curves, we found that the intermolecular hydrogen bonds did not affect the entanglement densities but made the zero shear viscosities larger and the relaxation times longer.
\end{abstract}

Key Words: Miscible blend / Hydrogen bond / Rheology / Entanglement / Glass transition temperature

\section{INTRODUCTION}

A wide variety of polymer alloy materials have been developed over the past 70 years from the viewpoint that their physical properties can be controlled more easily than the synthesis of new polymers ${ }^{1,2}$. In general, there are two types of polymer alloys: miscible and immiscible systems. For the latter case, the phase-separated morphologies play an essential role in determining their properties ${ }^{3}$. Therefore, the control of the morphologies has often been a topic in controlling their properties ${ }^{4-8}$. On the other hand, for the former case, the parameters that can control properties are only two: the pure component properties and intermolecular interactions. Miscible blends or miscible block copolymers generally exhibit the average properties of the constituent polymers. In that sense, designing the material properties of miscible blends is more straightforward than the case of phase-separated ones. While this is an advantage, the difficulty in developing synergies in their properties is also a disadvantage. However, there is still a possibility to create synergistic effects by strengthening the intermolecular interactions.

We have reported some studies on the dynamics of miscible alloys, including miscible blends ${ }^{9-12}$ and block

\footnotetext{
$\dagger$ Corresponding author.

E-mail : urakawa@chem.sci.osaka-u.ac.jp

Tel\&Fax: +81-6-6850-5538
}

copolymers $^{13,14)}$. However, we have not thoroughly evaluated the effect of interaction strength on the component dynamics quantitatively. Many experimental studies revealed that miscible blends without specific interaction exhibit dynamic heterogeneity when the difference of the component $T_{\mathrm{g}}$ is larger than $25^{\circ} \mathrm{C}^{9,15,16)}$. On the other hand, Yang and $\mathrm{Han}^{17)}$ reported that H-bonding miscible blends are more dynamically homogeneous: they exhibit relatively sharp single glass transition in DSC, and the time-temperature superposition principle apparently holds. These dynamical homogeneities can be due to the suppression of the concentration fluctuation ${ }^{18)}$ and the coupling of two segmental dynamics ${ }^{16)}$. H-bonding polymer blends are sometimes called "polymer complex" due to their specific one-to-one interaction ${ }^{19-23)}$.

Studies on the glass transition temperature $T_{\mathrm{g}}$ of hydrogen-bonding polymer blends revealed that intermolecular hydrogen bonds largely increase the $T_{\mathrm{g}}$ values, higher than the average values of the component $T_{\mathrm{g}}{ }^{24-27}$. Poly(2-vinyl pyridine) / poly (4-vinyl phenol) (2VPy / VPh) blend examined in this study is one example of such systems. The increase of $T_{\mathrm{g}}$ due to the formation of one-to-one hydrogen bonds (H-bonds), as schematically shown in Fig. 1, slows down the component polymer dynamics in various spatial and time scales. Formation of the associated structure provides a variety of material characteristics, not only $T_{\mathrm{g}}$ but also other dynamical properties. Dielectric relaxation studies on $\mathrm{H}$-bonded 


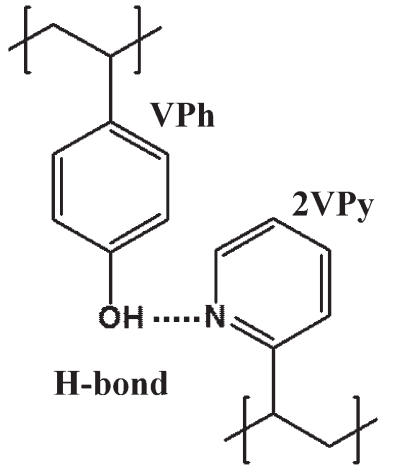

Fig. 1 Hydrogen bonding structure formed between VPh and 2VPy.

miscible blends showed that the segmental relaxation of both components occurred at the same rate even though their relaxation times were slower than the neat components, associated with the increase of $T_{\mathrm{g}}^{28)}$. However, it is still unclear how the slow dynamics in the rubbery and terminal regions are affected by such strong interaction. Yang and $\operatorname{Han}^{17)}$ demonstrated that the composition dependence of the zero-shear viscosity of the blend of VPh and 2VPy with similar molecular weights exhibited a maximum value at a certain blend composition $w_{2 \mathrm{VPy}}$ as same with $T_{\mathrm{g}}\left(w_{2 \mathrm{VPy}}\right)$. However, since their systems are nearly unentangled, it is still unveiled how the entanglement dynamics is affected by hydrogen bonding. They also evaluated the average viscosity in the blends but could not evaluate the dynamics of each component. Therefore, in this study we have examined the rheological behavior of the 2VPy / VPh system, where the component molecular weights are largely different: the $\mathrm{VPh}$ component is non-entangled, and only the 2VPy component are entangled. In such systems, the complication due to the effect of entanglements between different species ${ }^{29-31)}$ can be avoided. This paper discusses the blend composition dependence of the viscoelastic spectra in a wide frequency region including the terminal, rubbery, and glassy regions. We think the clarification of the rheological behavior is especially important from the perspective of the property control of such H-bonding polymer blends.

\section{EXPERIMENTAL}

The poly(2-vinyl pyridine) (2VPy) sample with molecular weight of $M_{\mathrm{w}}=1.82 \times 10^{5}$ was synthesized via living anionic polymerization. This sample was supplied by Profs Takano and Matsushita (Nagoya University). Two poly(4-vinyl phenol) (VPh) samples were supplied by JSR Corporation. Table I shows the characteristics of the samples used in this study.

The preparation method of the blends of $2 \mathrm{VPy} / \mathrm{VPh}$ is as
Table I Characteristics of poly(4-vinyl phenol) (VPh) and poly(2-vinyl pyridine) (2VPy).

\begin{tabular}{ccc}
\hline Code & $10^{3} M_{\mathrm{w}}$ & $M_{\mathrm{w}} M_{\mathrm{n}}$ \\
\hline VPh2 & 1.9 & 1.82 \\
VPh5 & 4.5 & 1.77 \\
2VPy182 & 182 & 1.06 \\
\hline
\end{tabular}

follows. Firstly the prescribed amounts of VPh and 2VPy polymers were dissolved in DMSO (common solvent), and then the ternary solution was re-precipitated in deionized water. The obtained precipitates were dried in a vacuum for one day at $120{ }^{\circ} \mathrm{C}$. Because of the precipitation operation in water, the blend compositions sometimes differed from those in the initially prepared DMSO solutions. Therefore, we determined the weight fractions of $2 \mathrm{VPy}\left(w_{\mathrm{VPy}}\right)$ for the finally dried samples by the elemental analysis with the equipment of MT-6 (YANACO, Japan). The details of the blend sample preparation were reported previously ${ }^{32)}$.

The glass transition temperature $T_{\mathrm{g}}$ for all the homopolymers and blend samples were determined with a differential scanning calorimeter (DSC 6220, Seiko Instruments Inc., Chiba, Japan). The rate of both heating and cooling processes was $10{ }^{\circ} \mathrm{C} \mathrm{min}^{-1}$. Three thermal scan cycles of 1 st heating-1 st cooling-2nd heating-2nd cooling-3rd heating were conducted in the temperature range of $30^{\circ} \mathrm{C} \sim 230^{\circ} \mathrm{C}$. We determined $T_{\mathrm{g}}$ in the 2 nd heating scan from the temperature at which the time derivative of the heat flow curve exhibited a peak. In the 3rd heating, we checked all the data to agree with the 2 nd heating scan.

Linear viscoelastic measurements were performed with a strain-controlled rheometer ARES G2 (TA instruments) using a small-amplitude oscillatory shear mode. Stainless steel parallel plates with $4 \mathrm{~mm}$ diameter were used for the measurements. The temperature range was from $90{ }^{\circ} \mathrm{C}$ to $230{ }^{\circ} \mathrm{C}$ depending on the $T_{\mathrm{g}}$ of each sample. The angular frequency $\omega$ range was from $100 \mathrm{rad} \mathrm{s}^{-1}$ to $0.1 \mathrm{rad} \mathrm{s}^{-1}$. The applied strains were confirmed to be small enough to be within the linear response regime for all the measurements.

\section{RESULTS AND DISCUSSIONS}

\subsection{Composition Dependence of Glass Transition Temperatures}

Figure 2 shows the dependence of $T_{\mathrm{g}}$ on the weight fraction of 2VPy $\left(w_{2 \mathrm{VPy}}\right)$ for the two blend systems, 2VPy182/ $\mathrm{VPh} 5$ and 2VPy182/VPh2, examined in this study along with the previously reported data for $2 \mathrm{VPy} 40\left(M_{\mathrm{w}}=3.9 \times 10^{4}, M_{\mathrm{w}} /\right.$ $M_{\mathrm{n}}=1.66$ ) blends with $\mathrm{VPh} 5$ and $\mathrm{VPh} 2$. As reported 
previously ${ }^{32)}$, the $w_{2 \mathrm{VPy}}$ dependence of $T_{\mathrm{g}}$ can be represented by the following modified Kwei equation using the component $T_{\mathrm{g}}$ values, $T_{\mathrm{g}, 2 \mathrm{VPy}}$ and $T_{\mathrm{g}, \mathrm{VPh}}$.

$$
T_{\mathrm{g}}=\frac{w_{2 \mathrm{VPy}} T_{\mathrm{g}, 2 \mathrm{VPy}}+k w_{\mathrm{VPh}} T_{\mathrm{g}, \mathrm{VPh}}}{w_{2 \mathrm{VPy}}+k w_{\mathrm{VPh}}}+q w_{2 \mathrm{VPy}}^{2} w_{\mathrm{VPh}}^{\alpha}
$$

Here, $w_{\mathrm{VPh}}=1-w_{2 \mathrm{VPy}}$, and $k, q$, and $\alpha$ are the parameters: ( $k$, $q, \alpha)=\left(1.28,158^{\circ} \mathrm{C}, 1.17\right)$ for $2 \mathrm{VP} 40 / \mathrm{VPh} 5$ and $(1.35$, $186^{\circ} \mathrm{C}, 1.18$ ) for $2 \mathrm{VP} 40 / \mathrm{VPh} 2$ blends $^{32)}$. Regarding the $\mathrm{VPh}$ component, their $T_{\mathrm{g}}$ are different depending on the molecular weight: $T_{\mathrm{g}, \mathrm{VPh}}=145.5^{\circ} \mathrm{C}$ (for $\mathrm{VPh} 5$ ) and $99.5^{\circ} \mathrm{C}$ (for $\mathrm{VPh} 2$ ). However, those of $2 \mathrm{VPy}$ are the same: $T_{\mathrm{g}, 2 \mathrm{VPy}}=98.9^{\circ} \mathrm{C}$ (for 2VPy40) and $98.7^{\circ} \mathrm{C}$ (for 2VPy182). It can be said that the glass transition behavior of the high molecular weight 2 VPy 182 blend system used in this study is almost the same as that of the $2 \mathrm{VPy} 40$ blend system.

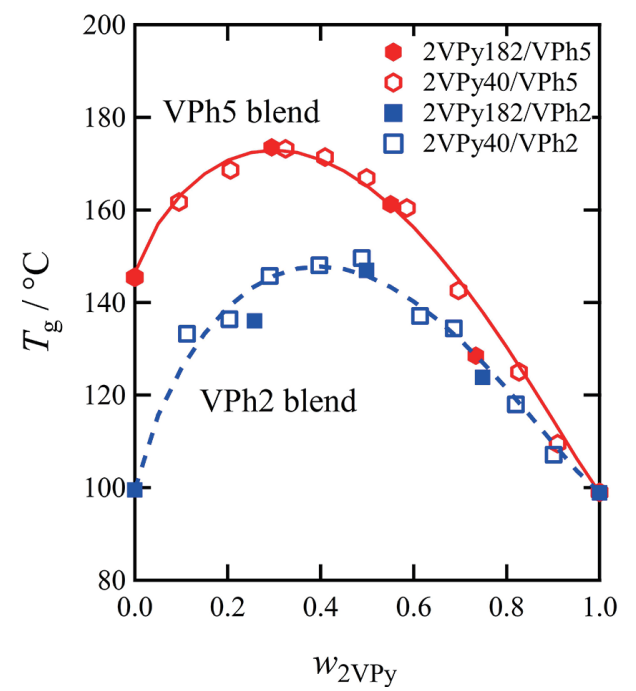

Fig. 2 Weight fraction dependence of $T_{\mathrm{g}}$ for 2VPy182 / VPh5, 2VPy39 / VPh5, 2VPy182 / VPh2, and 2VPy40 / VPh2 blends. The data of 2 VPy40 blends were already reported ${ }^{32)}$. The solid and dashed lines represent the modified Kwei equation (Eq 1).
The $T_{\mathrm{g}}\left(w_{2 \mathrm{VPy}}\right)$ of the $\mathrm{VPh} 2$ blend system has its peak position at $w_{2 \mathrm{VPy}} \sim 0.4$, even though the component $T_{\mathrm{g}} \mathrm{s}$ are almost the same. As discussed in our previous paper, we believe this is because the $\mathrm{VPh}$ component forms hydrogen bonds between $\mathrm{OH}-\mathrm{OH}$ groups (self-H-bonding), which reduces the contribution to the hetero-hydrogen bonds with pyridine groups of VPh shown in Fig. 1. The stoichiometric ratio of the hydrogen bond formed between $\mathrm{VPh}$ and 2VPy is $1: 1$ in the monomer units. However, due to the effect of selfH-bonding of the VPh component, an ideal hydrogen bonding structure having the stoichiometric ratio of 1:1 may be formed at $w_{2 \mathrm{VPy}}<0.5$. As will be discussed later, this effect also appears in the rheological behavior.

\subsection{Viscoelastic Spectra of 2VPy/VPh Blends}

The frequency $\omega$ dependence of the storage modulus $G^{\prime}$ and loss modulus $G^{\prime \prime}$ were measured for the two blend systems, 2VPy182/VPh5 and 2VPy182/VPh2, with three compositions, and the composite curves were constructed: Fig. 3 and Fig. 4, respectively show the reduced frequency dependence of $G^{\prime}$ and $G^{\prime \prime}$ of all the blend data, including those of the neat $2 \mathrm{VPy} 182, \mathrm{VPh} 5$, and $\mathrm{VPh} 2$. The reference temperature was set at $160^{\circ} \mathrm{C}$. It should be noted that this is the first time that the viscoelastic spectra of $2 \mathrm{VPy} / \mathrm{VPh}$ blends have been measured from the glass to the termination region. In the construction of these master curves, we found that the time-temperature superposition principle apparently held for these systems over a wide temperature range except for $\mathrm{VPh} 2$ and VPh5 homopolymer systems. In particular, for the VPh2 system, a slight temperature-dependent change in the shape of $G^{\prime}$ is observed at the lowest frequency side: the higher the temperature, the stronger the $\omega$-dependence of $G^{\prime}$. This may reflect the dissociation of the self-hydrogen bonds between $\mathrm{OH}$ groups at high temperatures. On the other hand, such

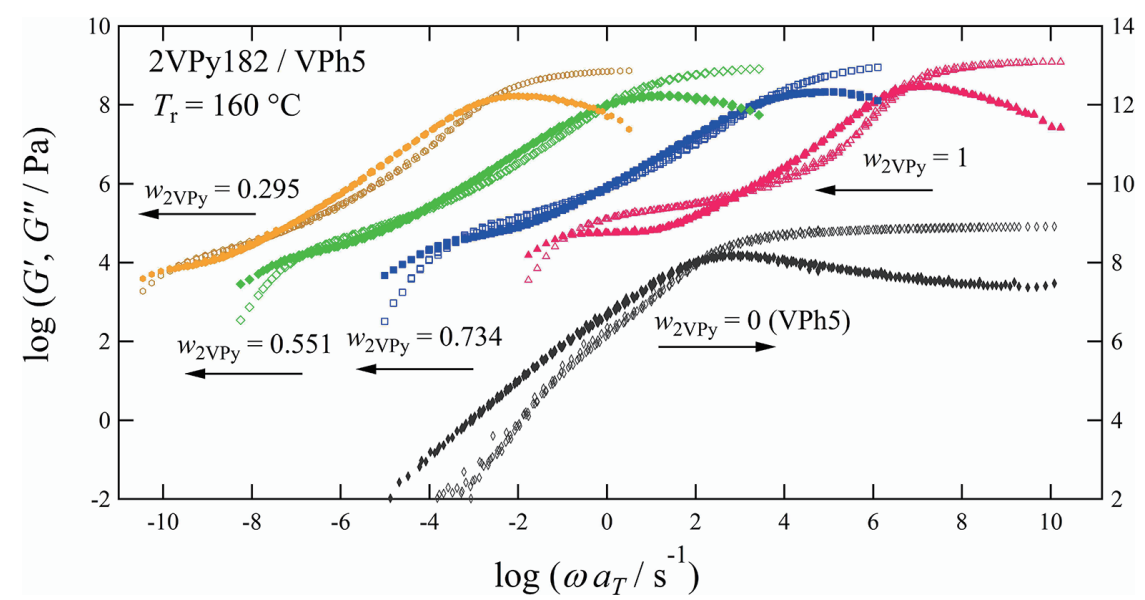

Fig. 3 Composite curves of $G^{\prime}$ (open markers) and $G^{\prime \prime}$ (filled markers) for $2 \mathrm{VPy} 182 / \mathrm{VPh} 5$ blends with $w_{\mathrm{VPy}}=0,0.295,0.551,0.734$, and 1 at $160{ }^{\circ} \mathrm{C}$. Those of $w_{\mathrm{VPy}}=0$ are plotted on the right-hand axis to avoid data overlapping. 


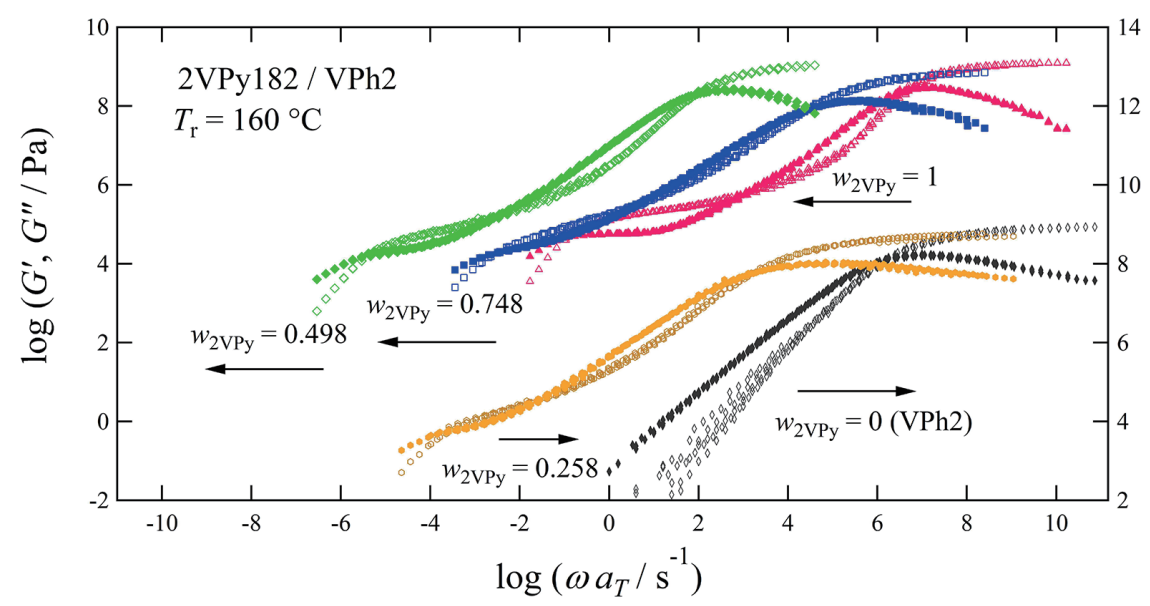

Fig. 4 Composite curves of $G^{\prime}$ (open markers) and $G^{\prime \prime}$ (filled markers) for $2 \mathrm{VPy} 182 / \mathrm{VPh} 2$ blends with $w_{\mathrm{VPy}}=0,0.258,0.498,0.748$, and 1 at $160{ }^{\circ} \mathrm{C}$. The data of $w_{\mathrm{VPy}}=1$ is the same as that shown in Fig. 3. Those of $w_{\mathrm{VPy}}=0$ and 0.258 are plotted on the right-hand axis to avoid data overlapping.

behavior was not observed in the blend systems, suggesting that the H-bonding between VPh and 2VPy (hetero-hydrogen bonding) is strong. In other words, the associated structure does not change much in the measurement temperature range. This behavior is consistent with the literature data ${ }^{17)}$.

From the shapes of the $G^{\prime}$ and $G^{\prime \prime}$ spectra for $\mathrm{VPh} 2$, VPh5, and 2VPy182 homopolymer systems, we can find that $2 \mathrm{VPy}$ is well entangled because of the appearance of the plateau region at $\log \left(\omega a_{\mathrm{T}}\right)=0 \sim 2$, while the two VPhs are non-entangled systems. Furthermore, $\mathrm{VPh} 5$ shows the Rouse mode as the shoulders in both $G^{\prime}$ and $G^{\prime \prime}$ on the low $\omega$ side, but for VPh2 no such shoulder exists. This is also consistent by considering that VPh2 consists of only two or three Rouse segments, whose molecular weight is reported for polystyrene having a similar structure to $\mathrm{VPh}$ to be $850^{33)}$. For the spectral shapes of the blend systems, they are broader compared with that of 2VPy. We will discuss this point in section 3.4 .

Regarding the glass mode peaks in the $G^{\prime \prime}$ spectra observed on the high-frequency side, we can see that the peak frequencies for the $\mathrm{VPh} 5$ blend with $\mathrm{w}_{2 \mathrm{VPy}}=0.295$ and for the $\mathrm{VPh} 2$ blend with the $w_{2 \mathrm{VPy}}=0.498$ locate at the lowest $\omega a_{\mathrm{T}}$. These behaviors are consistent with the functional forms of $T_{\mathrm{g}}\left(w_{2 \mathrm{VPy}}\right)$ shown in Fig. 2 : the highest $T_{\mathrm{g}}$ values among the three compositions in the $\mathrm{VPh} 5$ and $\mathrm{VPh} 2$ systems were $w_{2 \mathrm{VPy}}=0.295$ and $w_{2 \mathrm{VPy}}=0.498$, respectively, i.e., the $T_{\mathrm{r}}-T_{\mathrm{g}}$ values are the lowest for these compositions. The relationship between $T_{\mathrm{g}}$ and the rheological spectra will be discussed based on the shift factors in the next section.

\subsection{Temperature Dependence of Shift Factors}

Figure 5 shows the temperature dependence of the shift factors $a_{\mathrm{T}}$ for (a) 2VPy182 / VPh5 and (b) 2VPy182 / VPh2 blends with various compositions used to construct the
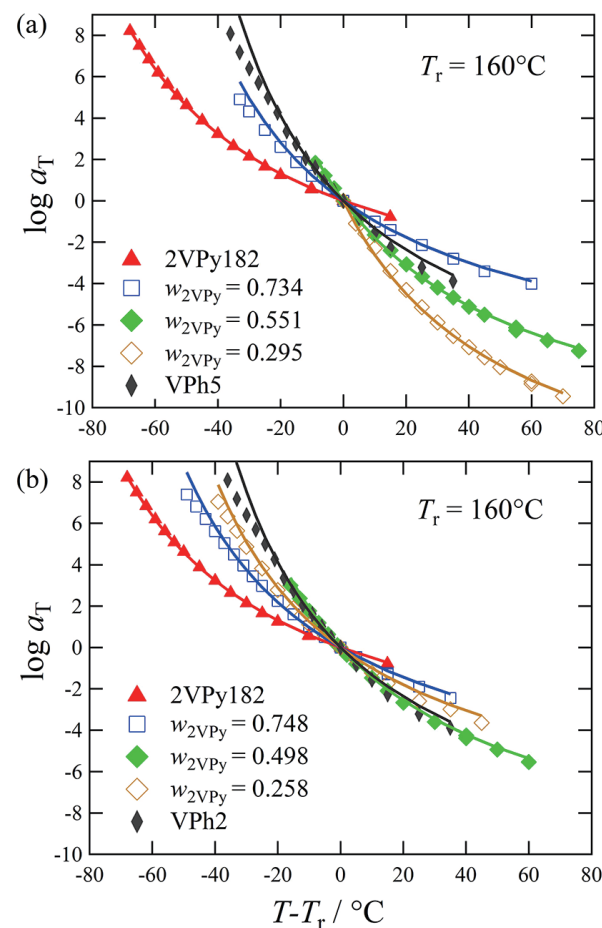

Fig. $5 T-T_{\mathrm{r}}$ dependence of the shift factors for (a) 2VPy182/VPh5 and (b) 2VPy182 / VPh2 blends with various compositions. The solid lines represent the fit curves by the WLF equation.

composite curves shown in Figs. 3 and 4. Reflecting the large $T_{\mathrm{g}}$ difference for the blend samples, $\log a_{\mathrm{T}}$ curves at the same reference temperature $\left(T_{\mathrm{r}}=160^{\circ} \mathrm{C}\right)$ are largely different. First, we fitted the $a_{\mathrm{T}}$ data of the neat 2VPy182 using the Williams Landel Ferry (WLF) equation.

$$
\log a_{T}=-\frac{C_{1}\left(T-T_{r}\right)}{C_{2}+T-T_{r}}
$$

We obtained the values of $C_{1}=6.805$ and $C_{2}=124.03{ }^{\circ} \mathrm{C}$ with $T_{\mathrm{r}}=160^{\circ} \mathrm{C}$. In general, the $C_{1}$ and $C_{2}$ values become almost universal even for different $T_{\mathrm{g}}$ samples by setting the appropriate reference temperatures: $T_{\mathrm{r}}=T_{\mathrm{g}}+$ constant. Based on this property, we moved the WLF curve fitted to the 2VPy 
Table II $T_{\mathrm{r}}^{*}$ and $T_{\mathrm{g}}$ for $2 \mathrm{VPy} 182 / \mathrm{VPh} 5$ and $2 \mathrm{VPy} 182 / \mathrm{VPh} 2$ blends at several compositions.

\begin{tabular}{c|ccc}
\hline System & $w_{2 \text { VPy }}$ & $T_{\mathrm{r}}{ }^{*} /{ }^{\circ} \mathrm{C}$ & $T_{\mathrm{g}} /{ }^{\circ} \mathrm{C}$ \\
\hline 2VPy182 / VPh5 & 1 & 160 & 98.7 \\
& 0.734 & 196.0 & 127.5 \\
& 0.551 & 220.1 & 161.2 \\
& 0.295 & 232.0 & 170.9 \\
& 0 & 209.1 & 145.5 \\
\hline 2VPy182 / VPh2 & 1 & 160 & 98.7 \\
& 0.748 & 185.5 & 129.9 \\
& 0.498 & 212.3 & 146.9 \\
& 0.258 & 197.0 & 136.0 \\
& 0 & 165.5 & 99.5 \\
\hline
\end{tabular}

(a)
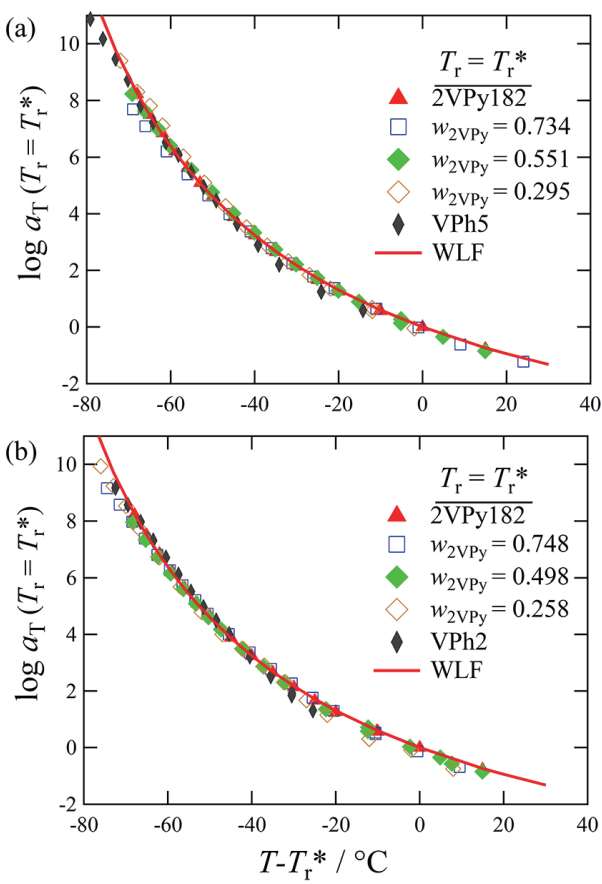

Fig. 6 Universal shift factors obtained by setting an appropriate reference temperature $T_{\mathrm{r}}^{*}$ for each blend.

data onto the other data through the horizontal and vertical shifts. The precise method has been reported previously ${ }^{34)}$. The fit-results are shown by the solid lines in Fig. 5, demonstrating that a single WLF function can represent almost all the data.

This operation enables us to determine a new reference temperature $T_{\mathrm{r}}{ }^{*}$ for each sample. Namely, by changing $T_{\mathrm{r}}$ $\left(160{ }^{\circ} \mathrm{C}\right)$ to $T_{\mathrm{r}}{ }^{*}$, the $a_{\mathrm{T}}$ curves can be superposed. The results are shown in Fig. 6, indicating that the superposition works well. Thus obtained $T_{\mathrm{r}}^{*}$ values are listed in Table II along with the $T_{\mathrm{g}}$ values determined by DSC. The plot of $T_{\mathrm{r}}^{*}$ vs. $T_{\mathrm{g}}$ is shown in Fig. 7, demonstrating a reasonable correlation between $T_{\mathrm{r}}^{*}$ and $T_{\mathrm{g}}$ : the relation of $T_{\mathrm{r}}^{*}=T_{\mathrm{g}}+64{ }^{\circ} \mathrm{C}$ approximately holds. This result suggests that the strong hydrogen bonding between 2VPy and VPh contributes equally to the change in $T_{\mathrm{g}}$ and the change in complex modulus. In other

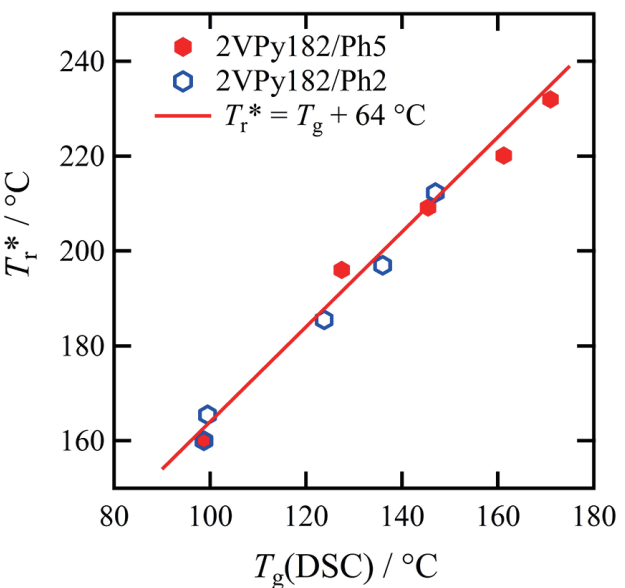

Fig. 7 Comparison of $T_{\mathrm{r}}^{*}$ obtained by the rheological shift factors with $T_{\mathrm{g}}$ determined by the differential scanning calorimetry.

words, the WLF analysis based on the free volume theory, which is valid for polymer systems without specific interactions, can be applied to the H-bonding miscible blend, although the H-bonding interaction strongly affects the glass transition and the molecular motion of polymers.

\subsection{Comparison of the Viscoelastic Spectra in the Iso-Frictional State}

Figures 8 and 9 show (a) $G^{\prime}\left(a_{\mathrm{T}} \omega\right)$ and (b) $G^{\prime \prime}\left(a_{\mathrm{T}} \omega\right)$ at $T_{\mathrm{r}}{ }^{*}$, i.e., in the iso-frictional state. Here, the horizontal shifts from $160{ }^{\circ} \mathrm{C}$ to $T_{\mathrm{r}}^{*}$ were calculated from the shift factor shown in Fig. 6. In these figures, the $G^{\prime}\left(a_{\mathrm{T}} \omega\right)$ and $G^{\prime \prime}\left(a_{\mathrm{T}} \omega\right)$ curves at $160{ }^{\circ} \mathrm{C}$ were moved only horizontally, not vertically, meaning that the absolute values of $G^{\prime}$ and $G^{\prime \prime}$ are those of $160^{\circ} \mathrm{C}$. These comparison indicates that the glass modes observed in the frequency range higher than $10^{6} \mathrm{~s}^{-1}$ overlap each other in the iso-frictional state. This is a natural result since the glass mode is a local relaxation, and its relaxation time is supposed to be the same under iso-frictional condition. In the glass to rubber transition region $\left(10^{4} \sim 10^{6} \mathrm{~s}^{-1}\right)$, both $G^{\prime}$ and $G^{\prime \prime}$ of the blends are slightly broadened compared to the 2VPy homopolymer. This suggests that the association and dissociation of hydrogen bonds may occur in this region. In the rubbery plateau region $\left(10^{0} \sim 10^{4} \mathrm{~s}^{-1}\right)$, the height of $G^{\prime}$ decreases as increasing the $\mathrm{VPh}$ content. In the terminal region (below $10^{0} \mathrm{~s}^{-1}$ ), both the heights of $G^{\prime}$ and $G^{\prime \prime}$ are decreased, but the peak positions of $G^{\prime \prime}$ does not seem to change much with $w_{2 \mathrm{VPy}}$.

First, in order to evaluate the concentration dependence of the entanglement density, the plateau modulus $G_{\mathrm{N}}$ was determined as the value of $G^{\prime}$ when $\tan \delta\left(=G^{\prime \prime} / G^{\prime}\right)$ shows a minimum. This method enables us to unambiguously determine the representative modulus values even when the $G^{\prime}$ does not show a clear plateau region. Some other methods 

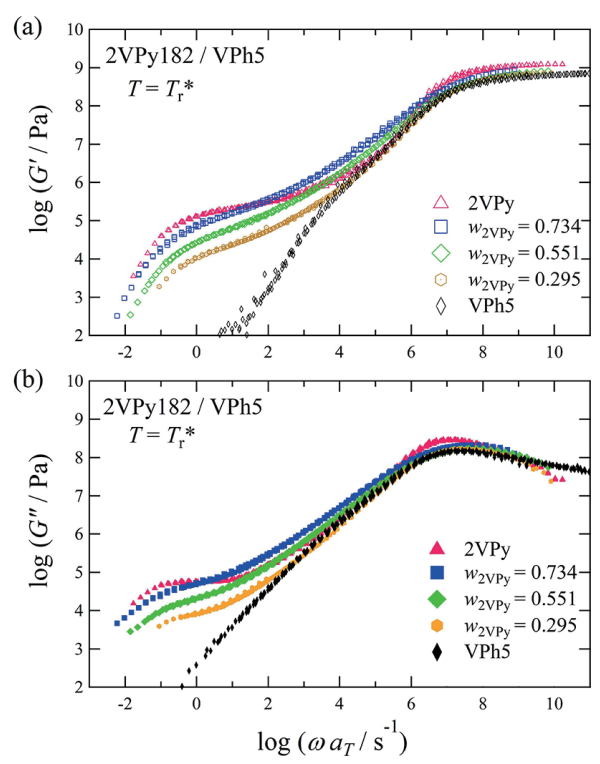

Fig. 8 (a) $G^{\prime}$ and (b) $G^{\prime \prime}$ spectra for 2VPy $182 / \mathrm{VPh} 5$ blends with $w_{2 \mathrm{VPy}}$ indicated in the figure at $T=T_{\mathrm{r}}^{*}$.
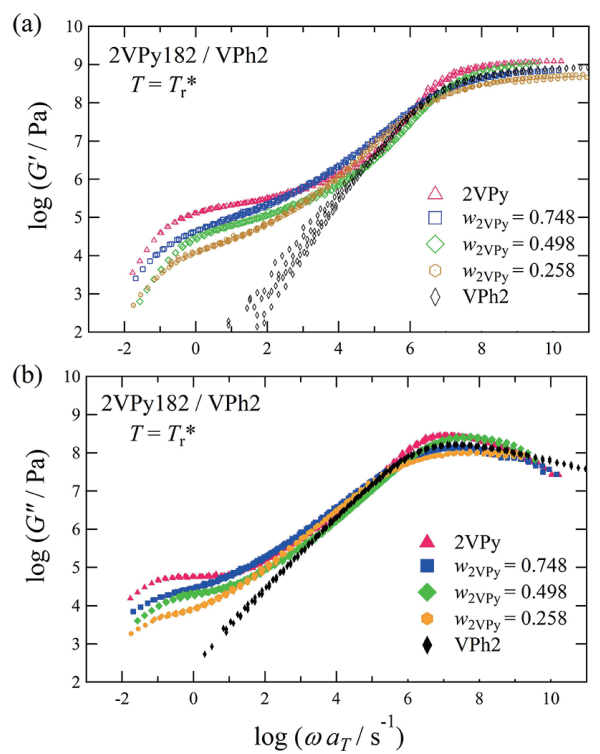

Fig. 9 (a) $G^{\prime}$ and (b) $G^{\prime \prime}$ spectra for 2VPy $182 / \mathrm{VPh} 2$ blends with $w_{\mathrm{VPy}}$ indicated in the figure at $T=T_{\mathrm{r}}^{*}$.

have been reported so far ${ }^{35}$, but most of them cannot be used unless $G^{\prime \prime}$ shows a clear peak in the terminal region. Therefore, it is difficult to apply such methods to these blend systems where $G^{\prime \prime}$ does not exhibit a clear peak except for neat $2 \mathrm{VPy}$. Only Wu's method ${ }^{36)}$ using the crosspoint $\left(G_{\mathrm{x}}\right)$ of $G^{\prime}$ and $G^{\prime \prime}$ $\left(G_{\mathrm{x}}=G^{\prime}=G^{\prime \prime}\right)$ at a frequency $\omega_{\mathrm{x}}$ given by Eq 3 is applicable for the data shown in Figs. 3 and 4 to determine the plateau modulus.

$$
\log G_{\mathrm{N}}=\log G_{\mathrm{X}}+0.38+\frac{2.63 \log \frac{M_{w}}{M_{n}}}{1+2.45 \log \frac{M_{w}}{M_{n}}}
$$

This equation relates the $M_{\mathrm{w}} / M_{\mathrm{n}}$ ratio and $G_{\mathrm{x}}$ to $G_{\mathrm{N}}$. In the blends examined here, hydrogen bonding interaction rather than the molecular weight distribution affects the shapes of $G^{\prime}$ and $G^{\prime \prime}$; however, we use the $M_{\mathrm{w}} / M_{\mathrm{n}}$ ratio of $2 \mathrm{VPy}(1.06)$ to estimate $G_{\mathrm{N}}$ for the confirmation of the $G_{\mathrm{N}}$ values. The $w_{2 \mathrm{VPy}}$ dependences of $G_{\mathrm{N}}$ determined from the above-mentioned two methods are shown in Fig. 10. We can see that both ways give similar $G_{\mathrm{N}}$ values, and they are nearly proportional to $w_{2 \mathrm{VPy}}{ }^{2}$. In the entangled polymer solution (polymer / low molecular weight diluent system), the plateau modulus is known to be proportional to the $2 \sim 2.3$ power of the polymer volume fraction $\phi^{37,38)}$. (Because the densities of 2VPy and $\mathrm{VPh}$ are nearly equal, $1.16 \mathrm{~g} \mathrm{~cm}^{-3}$ and $1.15 \mathrm{~g} \mathrm{~cm}^{-3}$, respectively, it is not necessary for these blends to distinguish the volume fraction from the weight fraction.) From the $w_{2 \mathrm{VPy}}{ }^{2}$ dependence of $G_{\mathrm{N}}$, we think that the entanglement network consists of only 2VPy182 chains, and the low molecular weight $\mathrm{VPh}$ can be simply regarded as a plasticizer. In other words, non-entangled VPh does not help increase the entanglement density even if it forms hydrogen bonds with $2 \mathrm{VPy}$.

Next, we focus on the terminal relaxation region. In the low frequency region, the relaxation of the entangled network of the high molecular weight 2VPy182 component is observed. For the 2VPy182 homopolymer system, the terminal flow behavior, $G^{\prime} \sim \omega^{2}$, and $G^{\prime \prime} \sim \omega$ appears. However, for the blend systems, the terminal spectra are slightly broadened, and the terminal exponents are somewhat weaker. This means that a long relaxation time component exists in the blend systems, suggesting the existence of hydrogen-bonded aggregates even at high temperatures where termination relaxation appears.

Since the behavior of $G^{\prime \prime} \sim \omega$ is barely observed for some blend samples, we plotted $G^{\prime \prime} / \omega$ against $\omega$ for all the data and superimposed them by the vertical shift to estimate the plateau values at $\omega \rightarrow 0$, which correspond to the zero shear viscosity $\eta_{0}\left(=\lim _{\omega \rightarrow 0} G^{\prime \prime} / \omega\right)$. As for the relaxation time, we examine two different average relaxation times. One is the crosspoint relaxation time $\tau_{\mathrm{x}}$ defined as the inverse of the frequency $\omega_{\mathrm{x}}$ at which $G^{\prime}$ and $G^{\prime \prime}$ intersect each other (close to the peak position of $\left.G^{\prime \prime}\right)$. The other is so-called the first-moment relaxation time $\tau_{\mathrm{n}}$ defined as $\tau_{\mathrm{n}}=\eta_{0} / G_{\mathrm{N}}{ }^{39)}$. Figure 11 shows the $w_{2 \mathrm{VPy}}$ dependence of thus determined $\eta_{0}, \tau_{\mathrm{x}}$, and $\tau_{\mathrm{n}}$. In these values, there is no apparent difference between the two blend systems: 2VPy182/VPh5 and 2VPy182/VPh2. This is because of the small viscosity difference between $\mathrm{VPh} 5$ and $\mathrm{VPh} 2$ at $T_{\mathrm{r}}^{*}\left(\eta_{0}=398 \mathrm{~Pa}\right.$ s for VPh5 and $281 \mathrm{~Pa} \mathrm{~s}$ for VPh2). In Fig. 11, linear approximations were made for the $w_{2 \mathrm{VPy}}$ dependences of these three valuables, and the slopes obtained by the least-squares method are also shown. In an 


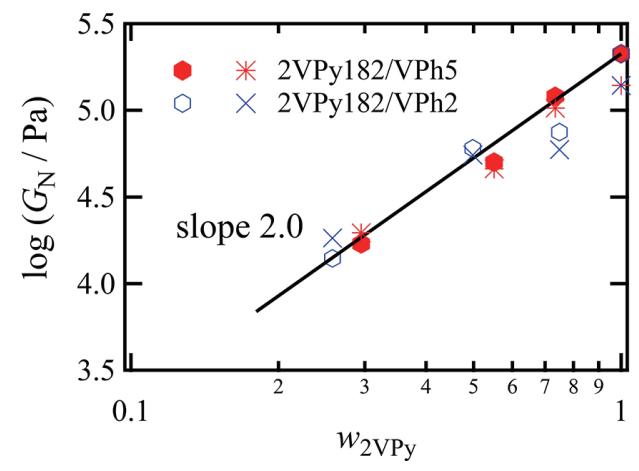

Fig. 10 Weight fraction dependence of the plateau modulus $G_{\mathrm{N}}$ determined from two methods: $\tan \delta$ minimum method (hexagonal markers) and Eq 3 (asterisk and cross markers) for 2VPy 182 / VPh5 and 2VPy182 $/ \mathrm{VPh} 2$ blends.

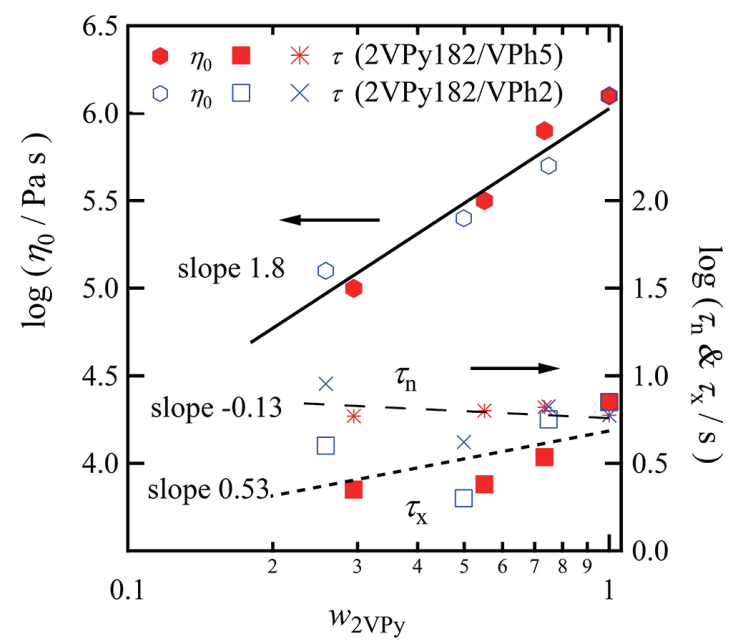

Fig. 11 Weight fraction dependence of the zero share viscosities and two different averaged relaxation times, $\tau_{\mathrm{n}}$ (asterisk and cross markers) and $\tau_{\mathrm{x}}$ (square markers) for 2VPy182 / VPh5, and 2VPy182/VPh2 blends at $T=T_{\mathrm{r}}^{*}$.

entangled polymer solution system without any specific interaction, the concentration dependence of the viscosity and relaxation time under iso-frictional conditions is expressed by the following equations (in the concentrated to bulk region $)^{38)}$.

$$
\eta_{0} \sim \phi^{3.6}, \tau \sim \phi^{1.3}
$$

The observed slopes for $\eta_{0}, \tau_{\mathrm{x}}$, and $\tau_{\mathrm{n}}$ in Fig. 11 (1.8, 0.53, -0.13 ) are much smaller than the powers in Eq 4 (3.6 and 1.3). These weak concentration dependences observed here can be qualitatively explained by considering that 2VPy chains aggregate via multiple $\mathrm{H}$-bonds with VPh chains. For example, if the $\mathrm{H}$-bonded association structure becomes larger by an increase in VPh concentration (a decrease in $w_{2 \mathrm{VPy}}$ ) at $T_{\mathrm{r}}^{*}$, the relaxation time and viscosity will increase. The stoichiometric ratio of the association between $2 \mathrm{VPy}$ and $\mathrm{VPh}$ is $1: 1$, but as discussed in section 3.1, the 1:1 aggregation is expected to occur at $w_{2 \mathrm{VPy}}<0.5$. Therefore, the associated structure of 2VPy via the H-bonding with VPh may be initially developed with decreasing $w_{2 \mathrm{VP} y}$, but below a certain $w_{2 \mathrm{VPy}}$ $(<0.5)$, it will remain unchanged. The decrease in the entanglement density by increasing the VPh content competes with the increase of the aggregation size, resulting in a weaker $w_{2 \mathrm{VPy}}$ dependence of $\eta_{0}, \tau_{\mathrm{x}}$, and $\tau_{\mathrm{n}}$ than that for typical entangled polymer solution systems. It is noted that the $w_{2 \mathrm{VPy}}$ dependence of $\tau_{\mathrm{x}}$ and $\tau_{\mathrm{n}}$ are different. This can be understood by considering that $\tau_{\mathrm{n}}$ is the average relaxation time with higher weight on the long-time component than $\tau_{\mathrm{x}}$. The difference between the two relaxation times slightly increases with decreasing $w_{2 \mathrm{VP} y}$, indicating that the relaxation time distribution becomes somewhat broader at lower $w_{2 \mathrm{VPy}}$.

The aggregation size should be a function of temperature, which means that the time-temperature superposition principle does not hold ${ }^{40)}$. However, in this experiment, at least no significant breakdown of the time-temperature superposition principle was observed. This suggests that the hydrogen-bonded aggregates are retained without dissociation even at the high temperatures where the termination region was measured. We think a more detailed experimental investigation of the aggregate formation is necessary in the future.

\section{CONCLUSIONS}

We conducted DSC and rheological measurements on the two blend systems, 2VPy182/VPh5 and 2VPy182/VPh2, with composition from 1:0 to 0:1. The glass transition temperatures of these blends were consistent with our previously reported results for 2VPy40/VPh5 and 2VPy40/VPh2, and the modified Kwei equation could represent the functional form of $T_{\mathrm{g}}\left(w_{2 \mathrm{VPy}}\right)$.

By using the time-temperature superposition principle, we could construct composite curves of $G^{\prime}(\omega)$ and $G^{\prime \prime}(\omega)$. WLF analysis of the temperature dependencies of the shift factors for all the blend compositions enabled us to obtain appropriate reference temperatures $T_{\mathrm{r}}{ }^{*} \mathrm{~s}$, which were approximately represented by $T_{\mathrm{r}}{ }^{*}=T_{\mathrm{g}}+64^{\circ} \mathrm{C}$.

From the comparison of the composite curves for both blends at $T=T_{\mathrm{r}}{ }^{*}$ (iso-frictional state), we found the following relations: (1) $G_{\mathrm{N}} \sim w_{2 \mathrm{VPy}}^{2}$, (2) $\eta_{0} \sim w_{2 \mathrm{VPy}}^{1.8}$, and (3) $\tau_{\mathrm{x}} \sim w_{2 \mathrm{VPy}}{ }^{0.53}, \tau_{\mathrm{n}} \sim w_{2 \mathrm{VPy}}{ }^{-0.13}$. The relation (1) indicated that the low molecular weight VPh component works just as a plasticizer for the entangled 2VPy component. However, the relations (2) and (3) suggested that the terminal flow of the 2VPy component is affected by the hydrogen bonding with the VPh component. 


\section{ACKNOWLEDGEMENTS}

The authors are grateful to Prof. A. Takano, Prof. Y. Matsushita, and JSR corporation for providing 2VPy and $\mathrm{VPh}$ samples. The financial support by the Grant-in-Aid for Scientific Research from the Ministry of Education, Culture, Sports, Science and Technology, Japan (grant No. 19H02777 $\&$ 19K05601) is acknowledged.

\section{REFERENCES}

1) Kotaka T, "Polymer Alloy: Kiso to ouyou", (1993), Tokyo Kagaku Dojin, Tokyo.

2) Utracki LA, Favis B, "Polymer alloys and blends", (1989), Marcel Dekker: New York.

3) Nishikawa K, Hirose Y, Urakawa O, Adachi K, Hatano A, Aoki Y, Polymer, 43, 1483 (2002).

4) Tran-Cong Q, Ohta T, Urakawa O, Phys Rev E, 56, R59 (1997).

5) Kataoka K, Urakawa O, Nishioka H, Tran-Cong Q, Macromolecules, 31, 8809 (1998).

6) Ohta T, Kataoka K, Urakawa O, Ohba T, Tran-Cong Q, Nuovo Cimento D, 20, 2061 (1998).

7) Tran-Cong Q, Kataoka K, Urakawa O, Phys Rev E, 57, R1243 (1998).

8) Hori H, Urakawa O, Yano O, Tran-Cong-Miyata Q, Macromolecules, 40, 389 (2007).

9) Urakawa O, Fuse Y, Hori H, Tran-Cong Q, Yano O, Polymer, 42, 765 (2001)

10) Hirose Y, Urakawa O, Adachi K, Macromolecules, 36, 3699 (2003).

11) Hori H, Urakawa O, Adachi K, Polym J, 35, 721 (2003).

12) Urakawa O, Ujii T, Adachi K, J Non Cryst Solids, 352, 5042 (2006).

13) Hirose Y, Urakawa O, Adachi K, J Polym Sci Part B: Polym Phys, 42, 4084 (2004).

14) Urakawa O, Kido M, Adachi K, Nihon Reoroji Gakkaishi (J Soc Rheol Jpn), 32, 189 (2004).

15) Watanabe H, Urakawa O, Korea-Aust Rheol J, 21, 235 (2009).

16) Urakawa $\mathrm{O}$, Adachi $\mathrm{K}$ In Book, "Effect of Intermolecular Interactions on the Dynamic Heterogeneity in Miscible
Polymer Blends", Adachi K, Sato T, Eds, 189, (2005), Osaka University Press.

17) Yang Z, Han CD, Macromolecules, 41, 2104 (2008).

18) Urakawa O, Ikuta H, Nobukawa S, Shikata T, J Polym Sci Part B: Polym Phys, 46, 2556 (2008).

19) Zhang XQ, Takegoshi K, Hikichi K, Polym J, 23, 79 (1991).

20) Dai J, Goh SH, Lee SY, Siow KS, Polym J, 26, 905 (1994).

21) Zhong ZK, Guo QP, Polym Int, 41, 315 (1996).

22) Jiang M, Li M, Xiang ML, Zhou H In Book, "Interpolymer complexation and miscibility enhancement by hydrogen bonding", Inoue S et al Eds, 121, (1999), Springer Berlin Heidelberg.

23) Kaczmarek H, Szalla A, Kaminska A, Polymer, 42, 6057 (2001).

24) Cesteros LC, Meaurio E, Katime I, Macromolecules, 26, 2323 (1993).

25) Coleman MM, Painter PC, Prog Polym Sci, 20, 1 (1995).

26) Kwei TK, J Polym Sci Pol Lett, 22, 307 (1984).

27) Demeftahi MV, Frechet JMJ, Polymer, 29, 477 (1988).

28) Zhang SH, Jin X, Painter PC, Runt J, Polymer, 45, 3933 (2004).

29) Wu SH, Polymer, 28, 1144 (1987).

30) Chiba T, Katashima T, Urakawa O, Inoue T, Nihon Reoroji Gakkaishi (J Soc Rheol Jpn), 48, 49 (2020).

31) Cai HJ, Ait-Kadi A, Brisson J, Journal of Applied Polymer Science, 93, 1623 (2004).

32) Urakawa O, Yasue A, Polymers, 11, 1153 (2019).

33) Inoue T, Osaki K, Macromolecules, 29, 1595 (1996).

34) Urakawa $\mathrm{O}$, Ikuta $\mathrm{H}$, Maji $\mathrm{S}$, Inoue $\mathrm{T}$, Nihon Reoroji Gakkaishi (J Soc Rheol Jpn), 46, 131 (2018).

35) Liu CY, He JS, van Ruymbeke E, Keunings R, Bailly C, Polymer, 47, 4461 (2006).

36) Wu SH, J Polym Sci Part B: Polym Phys, 27, 723 (1989).

37) Ferry JD, "Viscoelastic Properties of Polymers", $3^{\text {rd }}$ ed. (1980), John Wiley \& Sons, Inc.

38) Colby RH, Fetters LJ, Funk WG, Graessley WW, Macromolecules, 24, 3873 (1991).

39) Watanabe H, Prog Polym Sci, 24, 1253 (1999).

40) Zhang ZJ, Chen Q, Colby RH, Soft Matter, 14, 2961 (2018). 